\title{
Hemoglobin S/OArab: Retinal Manifestations of a Rare Hemoglobinopathy
}

\author{
Riley Sanders ${ }^{\mathrm{a}} \quad$ Victoria Ly $^{\mathrm{b}}$ Kinza Ahmad $^{\mathrm{a}} \quad$ Jesse Swift ${ }^{\mathrm{a}, \mathrm{c}}$ \\ Ahmed Sallam $^{a}$ Sami Uwaydat ${ }^{a}$ \\ a Harvey and Bernice Jones Eye Institute, University of Arkansas for Medical Sciences, Little \\ Rock, AR, USA; ${ }^{b}$ College of Medicine, University of Arkansas for Medical Sciences, Little \\ Rock, AR, USA; 'Southwest Eye Care, Albuquerque, NM, USA
}

\section{Keywords}

Hemoglobin $\mathrm{S} / \mathrm{O}_{\text {Arab }} \cdot$ Sickle cell retinopathy $\cdot$ Hemoglobinopathy $\cdot$ Retinal ischemia

\begin{abstract}
Hemoglobin $\mathrm{S} / \mathrm{O}_{\text {Arab }}\left(\mathrm{Hgb} \mathrm{S} / \mathrm{O}_{\text {Arab }}\right.$ ) disease is a rare hemoglobinopathy which presents similarly to sickle cell retinopathy, with only three prior reports that describe associated retinal findings. In this report, we present ophthalmic examination findings in 2 patients with $\mathrm{Hgb} \mathrm{S} / \mathrm{O}_{\text {Arab. }}$ One patient exhibited peripheral ischemia and sunburst lesions without neovascular disease, and the other patient developed proliferative retinopathy of both eyes and multiple posterior-pole branch retinal artery occlusions in one eye. To our knowledge, this is the first case of retinal arterial occlusive disease in $\mathrm{Hgb} \mathrm{S} / \mathrm{O}_{\mathrm{Arab}}$, and the first report of fundus autofluorescence and OCT angiography in $\mathrm{Hgb} / \mathrm{O}_{\text {Arab }}$ retinopathy.

\section{Introduction}

Hemoglobin $\mathrm{S} / \mathrm{O}_{\text {Arab }}\left(\mathrm{Hgb} \mathrm{S} / \mathrm{O}_{\text {Arab }}\right.$ ) is a rare hemoglobinopathy that causes sickling of red blood cells. This sickling causes vaso-occlusive signs and symptoms similar to those seen with sickle cell disease (Hgb SS and Hgb SC) [1]. The characteristic molecular pathology is hemoglobin comprised of two variant $\beta$-globin chains: $\beta-6$ glutamine to valine substitution ( $\mathrm{Hgb} \mathrm{S}$ ) 
and $\beta-121$ glutamine to lysine substitution $\left(\mathrm{Hgb} \mathrm{O}_{\mathrm{Arab}}\right)$. High-performance liquid chromatography, isoelectric electrophoresis, and mass spectrometry techniques are used to make the diagnosis [2]. Hgb S/O Arab occurs more frequently among those with Arabic heritage, but has been described in the USA, Eastern Europe, and Jamaica [1].

There is a paucity of literature on the retinal findings in patients with $\mathrm{Hgb} \mathrm{S} / \mathrm{O}_{\mathrm{Arab}}$, with the last report dating to 1979 , describing peripheral ischemia and neovascular sea fans as seen in sickle cell retinopathy (SCR) [3].

In this report, we present 2 patients with $\mathrm{Hgb} \mathrm{S} / \mathrm{O}_{\text {Arab }}$ retinopathy, one with peripheral ischemia and no neovascular disease, and one who developed advanced proliferative retinopathy in one eye and central retinal ischemia in the fellow eye. Multiple imaging modalities were used in diagnosis. These findings reinforce the notion that $\mathrm{Hbg} \mathrm{S} / \mathrm{O}_{\text {Arab }}$ retinopathy manifests similarly to SCR, and there is need for ophthalmic screening in this population.

\section{Case One}

A 23-year-old African-American female with $\mathrm{Hgb} \mathrm{S} / \mathrm{O}_{\text {Arab }}$ disease was referred to the retina clinic evaluation. At the time of initial examination, her best-corrected distance visual acuity was 20/20 in the right eye and 20/25 in the left eye. Anterior segment examination was within normal limits in both eyes. She was found to have slightly large cup/disc ratio of 0.6 and peripheral sunburst lesions in both eyes (Fig. 1a). Fundus autofluorescence showed retinal changes corresponding to the sunburst lesions, with hyperautofluorescent areas encircling hypoautofluorescent areas of RPE hyperplasia (Fig. 1b). Fluorescein angiography revealed arteriovenular anastomoses and peripheral retinal ischemia in both eyes without neovascularization (Fig. 2).

\section{Case Two}

A 37-year-old African-American female with $\mathrm{Hgb} \mathrm{S} / \mathrm{O}_{\text {Arab }}$ presented to the clinic with sudden decrease in vision of her right eye. On examination, her vision was hand motion in the right eye and 20/20 in the left eye. Pupils were reactive to light, with no relative afferent pupillary defect. Intraocular pressure and anterior segment examination were normal. There was a dense vitreous hemorrhage in the right eye causing a poor view to the posterior pole and periphery. In the left eye, the optic nerve had a cup/disc ratio of 0.5 and the macula was within normal limits. The retinal vessels were noted to be sclerotic in the temporal and nasal periphery. B-scan of the right eye revealed an attached retina, but there was evidence of tractional membranes in the posterior pole. Fluorescein angiography of the left eye showed extensive peripheral ischemia with "sea fanning" consistent with proliferative SCR (Fig. 3).

She underwent 23-G pars plana vitrectomy with membrane segmentation and endolaser in the right eye for the vitreous hemorrhage (Fig. 4a). Delamination was avoided where membranes were firmly adherent to the vascular arcades. At the 1-month follow-up appointment, she reported having sudden painless vision loss 2 days prior in her left eye. Her vision at this time was 20/100 in right eye and 20/50 in left eye. No relative afferent pupillary defect was noted. Fundus examination of the left eye revealed patchy areas of retinal whitening around the fovea (Fig. 4c), consistent with multiple branch retinal artery occlusions (BRAO). The patient was offered a fluorescein angiogram at this time to confirm the diagnosis, but she declined. OCT done a few weeks later showed residual tractional membranes in the right eye 
(Fig. 4b). In the left eye, inner retinal atrophy consistent with previous BRAO was seen (Fig. $4 d)$.

\section{Discussion}

Our cases document several possible retinal complications of $\mathrm{Hgb} \mathrm{S} / \mathrm{O}_{\mathrm{Arab}}$. In a literature search, there were only 3 previously reported cases of SCR secondary to Hgb S/O $\mathrm{O}_{\text {Arab }}$, with the last case reported in 1979 [1,3]. Authors described findings of occluded peripheral arterioles, hyper- and hypo-pigmented chorioretinal lesions, sunburst lesions, and neovascular sea fans. Drawings and fluorescein angiography photographs were included in their manuscript [3]. Color photographs and the characteristic findings of $\mathrm{Hgb} \mathrm{S} / \mathrm{O}_{\text {Arab }}$ on fundus autofluorescence have not been reported. Further, there have been no reported cases of BRAO secondary to Hgb $\mathrm{S} / \mathrm{O}_{\text {Arab. }}$

$\mathrm{Hgb} \mathrm{O}_{\text {Arab }}$ has been described to clinically manifest most similarly to Hgb SS. Patients with heterozygous and homozygous $\mathrm{Hgb} \mathrm{O}_{\text {Arab }}$ are typically asymptomatic, but homozygotes may have mild hemolytic anemia that the body usually compensates [4]. It has been found that Hgb $\mathrm{O}_{\text {Arab }}$ stabilizes the polymerization of Hgb S, which irreversibly sickles red blood cells [1]. Thus, patients with heterozygous Hgb S/0 Arab present with the same systemic disease severity as homozygous Hgb SS, including hemolytic anemia, jaundice, and vaso-occlusive complication [5].

In the eye, it is possible that $\mathrm{Hgb} \mathrm{S} / \mathrm{O}_{\mathrm{Arab}}$ could have properties of both $\mathrm{Hgb} \mathrm{SS}$ and $\mathrm{Hgb} \mathrm{SC}$ disease that lead to both vessel occlusion from sickling and relative peripheral retinal ischemia. More patients with Hgb SC disease have visual symptoms compared to those with Hgb SS disease, and the incidence of the neovascular proliferation is greater in Hgb SC disease (45\% in $\mathrm{Hgb} \mathrm{SC}$ disease and 11\% in Hgb SS disease) [6-8]. A possible mechanism for retinopathy in $\mathrm{Hgb} \mathrm{SC}$ disease is impaired oxygen transport to the peripheral retina leading to relative ischemia in which many cells remain alive, but oxygen starved, releasing VEGF and inducing neovascularization. Oxygen affinity decreases in red blood cells with $\mathrm{Hgb} S / \mathrm{O}_{\text {Arab }}$ [5]. This impairs oxygen transport and could subsequently cause relative ischemia similar to Hgb SC disease. As $\mathrm{Hgb} \mathrm{S} / \mathrm{O}_{\text {Arab }}$ causes sickling and vaso-occlusive disease similar to Hgb SS, sickling of the red blood cells could cause a complete occlusion of the retinal vessel leading to retinal infarction and cell death.

$\mathrm{Hgb} \mathrm{S/O}$ Arab retinopathy appears phenotypically similar to SCR. SCR evolves in 5 stages: (I) peripheral arteriolar occlusion, (II) arteriovenular anastomoses, (III) neovascular sea fans, (IV) vitreous hemorrhage, and (V) tractional retinal detachment [9] or rhegmatogenous retinal detachment [10]. Central retinal artery occlusion may also occur in Hgb SS [11] or SC [12]. OCT findings of SCR include outer retinal thinning and temporal macular atrophy [10]. OCT angiography is an emerging technology that may be better for quantifying central retinal capillary thinning and foveal avascular zone enlargement in SCR [10]. Fundus autofluorescence is also being investigated as a tool to detect early peripheral retinal changes in SCR and better understand its pathogenesis and progression [13]. As shown by our cases, these studies can be useful for retinal examination of $\mathrm{Hgb} \mathrm{S} / \mathrm{O}_{\mathrm{Arab}}$ patients as well, and demonstrate similar findings.

In conclusion, $\mathrm{Hgb} \mathrm{S} / \mathrm{O}_{\mathrm{Arab}}$ is a rare hemoglobinopathy that may cause both SCR and vasoocclusive disease. Patients known to have this hemoglobinopathy should be referred to an ophthalmologist. Due to the rarity of cases, multicenter studies are needed to further elucidate the epidemiology and prognosis of $\mathrm{Hgb} \mathrm{S} / \mathrm{O}_{\mathrm{Arab}}$ retinopathy. 


\section{Acknowledgments}

We are grateful to the Jones Eye Institute, University of Arkansas for Medical Sciences College of Medicine.

\section{Statement of Ethics}

The authors have no ethical conflicts to disclose. The patients gave written informed consent for the publication of their cases, including images.

\section{Disclosure Statement}

The authors have no conflicts of interest to declare.

\section{Funding Sources}

The authors have no funding support to disclose.

\section{Author Contributions}

Dr. Riley Sanders wrote and edited the manuscript. Kinza Ahmad examined the first patient and wrote portions of the manuscript. Dr. Jesse Swift examined the second patient and wrote portions of the manuscript. Victoria Ly wrote and edited portions of the manuscript. Dr. Sami Uwaydat is the attending physician for both patients; he examined both patients and wrote and edited the manuscript. All authors approved the final version of the manuscript.

\section{References}

1 Zimmerman SA, O’Branski EE, Rosse WF, Ware RE. Hemoglobin S/O(Arab): thirteen new cases and review of the literature. Am J Hematol. 1999 Apr;60(4):279-84.

2 Daniel YA, Turner C, Haynes RM, Hunt BJ, Dalton RN. Rapid and specific detection of clinically significant haemoglobinopathies using electrospray mass spectrometry-mass spectrometry. Br J Haematol. 2005 Aug;130(4):635-43.

3 Condon PI, Serjeant GR. Ocular findings in sickle cell-haemoglobin 0 Arab disease. Br J Ophthalmol. 1979 Dec;63(12):839-41.

4 Zacharia G, Maronge GF, Brazda FW, Boulmay BC. Hemoglobin SO-Arab and $\alpha$-thalassemia diagnosed in an adult: A case-based review of the hemoglobinopathies. Am J Med Sci. 2013 Oct;346(4):325-7.

5 Milner PF, Miller C, Grey R, Seakins M, DeJong WW, Went LN. Hemoglobin O arab in four negro families and its interaction with hemoglobin S and hemoglobin C. N Engl J Med. 1970 Dec;283(26):1417-25.

6 Welch RB, Goldberg MF. Sickle-cell hemoglobin and its relation to fundus abnormality. Arch Ophthalmol. 1966 Mar;75(3):353-62.

7 Clarkson JG. The ocular manifestations of sickle-cell disease: a prevalence and natural history study. Trans Am Ophthalmol Soc. 1992;90:481-504.

8 Speakman JS, Crookston JH, Mortimer CB, Robertson GL. Ocular manifestations of hemoglobin S-C disease. Can Med Assoc J. 1966 Mar;94(10):465-9.

9 Goldberg MF. Natural history of untreated proliferative sickle retinopathy. Arch Ophthalmol. 1971 Apr;85(4):428-37. 


\section{Case Reports in Ophthalmology}

\begin{tabular}{l|l}
\hline Case Rep Ophthalmol 2020;11:189-195 \\
\hline DOI: 10.1159/000507879 & $\begin{array}{l}\text { @ 2020 The Author(s). Published by S. Karger AG, Basel } \\
\text { www.karger.com/cop }\end{array}$ \\
\hline
\end{tabular}

Sanders et al.: $\mathrm{Hgb} \mathrm{S} / \mathrm{O}_{\text {Arab }}$ : Retinal Manifestations of a Rare Hemoglobinopathy

10 Menaa F, Khan BA, Uzair B, Menaa A. Sickle cell retinopathy: improving care with a multidisciplinary approach. J Multidiscip Healthc. 2017 Aug;10:335-46.

11 Liem RI, Calamaras DM, Chhabra MS, Files B, Minniti CP, Thompson AA. Sudden-onset blindness in sickle cell disease due to retinal artery occlusion. Pediatr Blood Cancer. 2008 Mar;50(3):624-7.

12 Fine LC, Petrovic V, Irvine AR, Bhisitkul RB. Correction-spontaneous central retinal artery occlusion in hemoglobin SC disease(1). Am J Ophthalmol. 2000 Dec;130(6):906-7.

13 Bowie EM. Spectralis HRA+OCT imaging of the retina with autofluorescence in sickle cell disease. 2010. Available from: https://clinicaltrials.gov/ct2/show/study/NCT01123369.
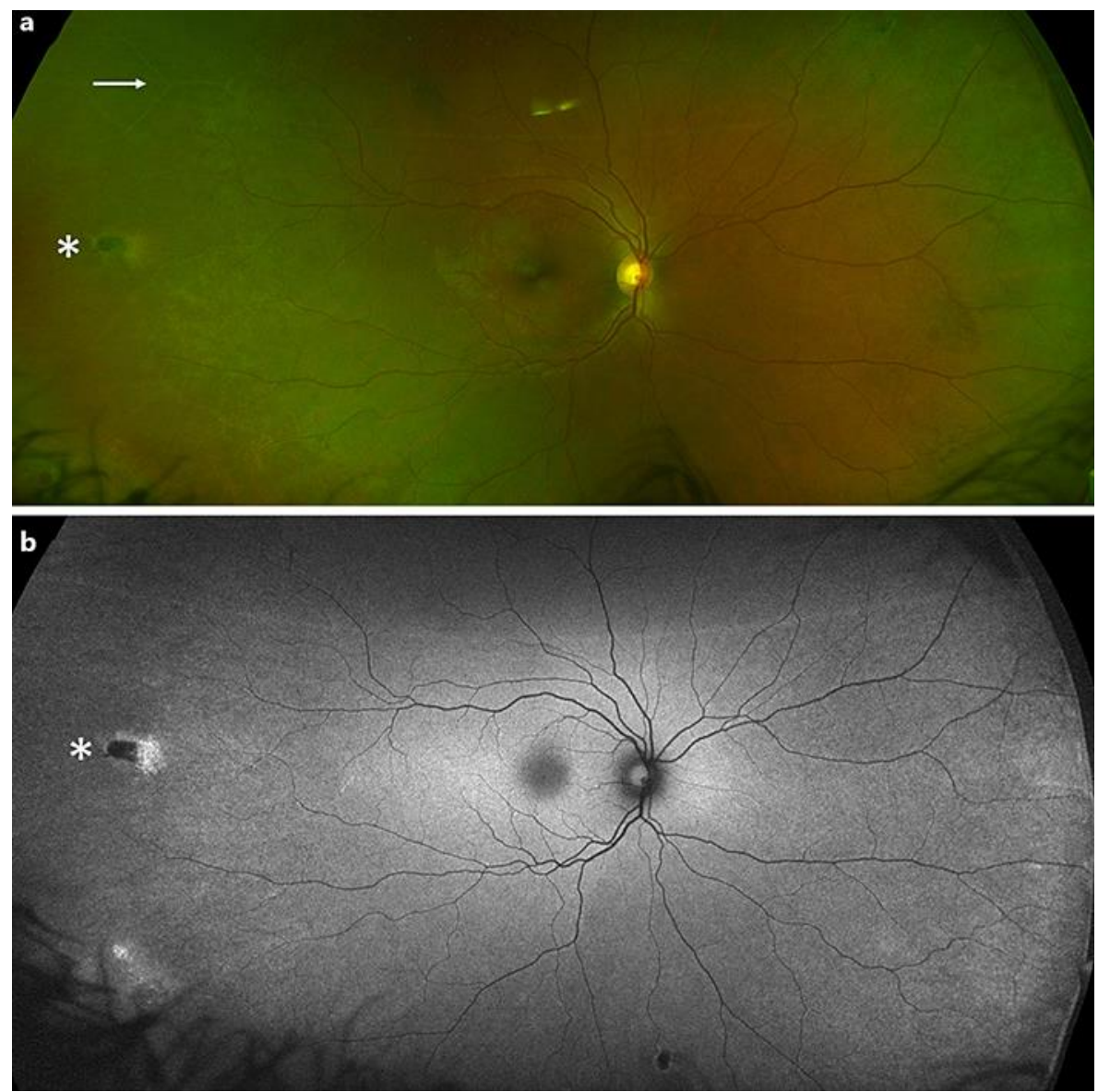

Fig. 1. a Red/green Optos ${ }^{\circledR}$ wide-field image demonstrates sclerotic vessels (thin arrow) and sunburst lesion (asterisk). b Optos wide-field fundus autofluorescence appearance. Sunburst (asterisk) appears as a hypoautofluorescent lesion surrounded by hyperautofluorescence. 


\section{Case Reports in Ophthalmology}

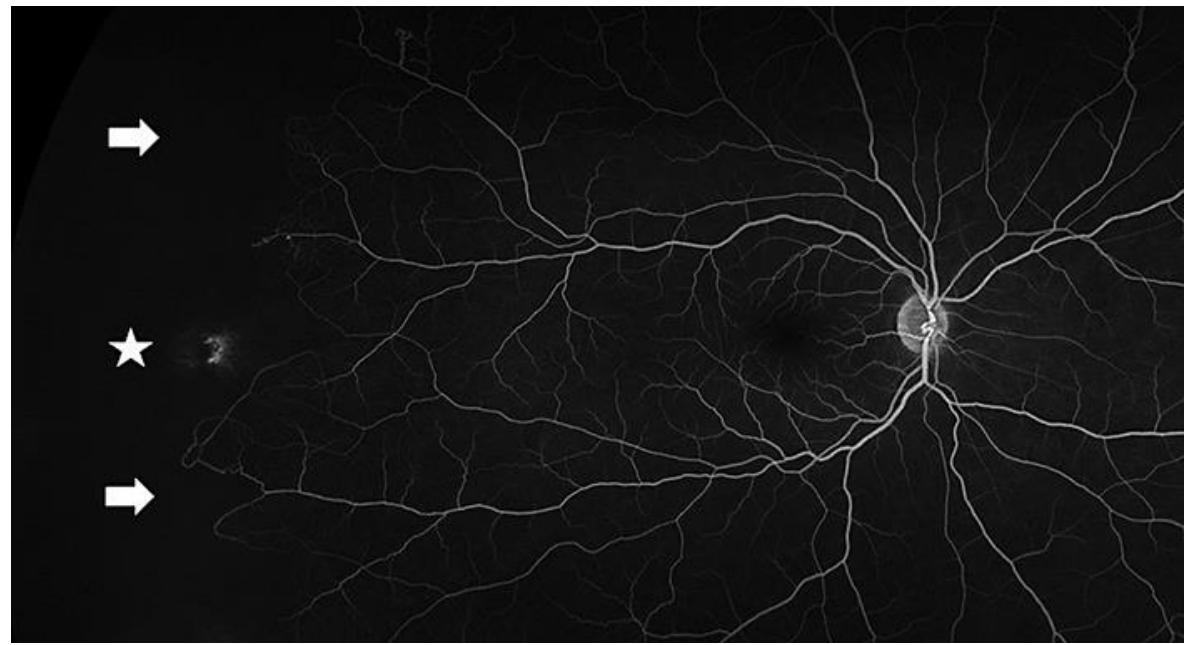

Fig. 2. Late-phase Optos ${ }^{\circledR}$ fluorescein angiography image taken of patient 1 shows peripheral ischemia (star) and arteriovenular anastomoses (bold arrows), but without any neovascular leakage.

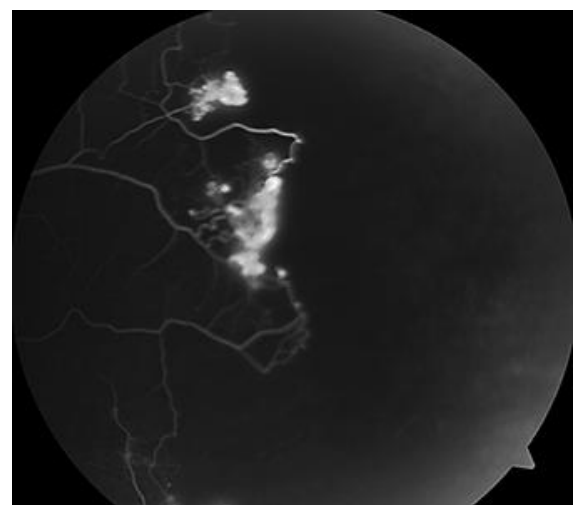

Fig. 3. Late-phase Optos ${ }^{\circledR}$ FA of patient 2 demonstrates arteriovenular anastomoses with areas of neovascular leakage. 


\section{Case Reports in Ophthalmology}
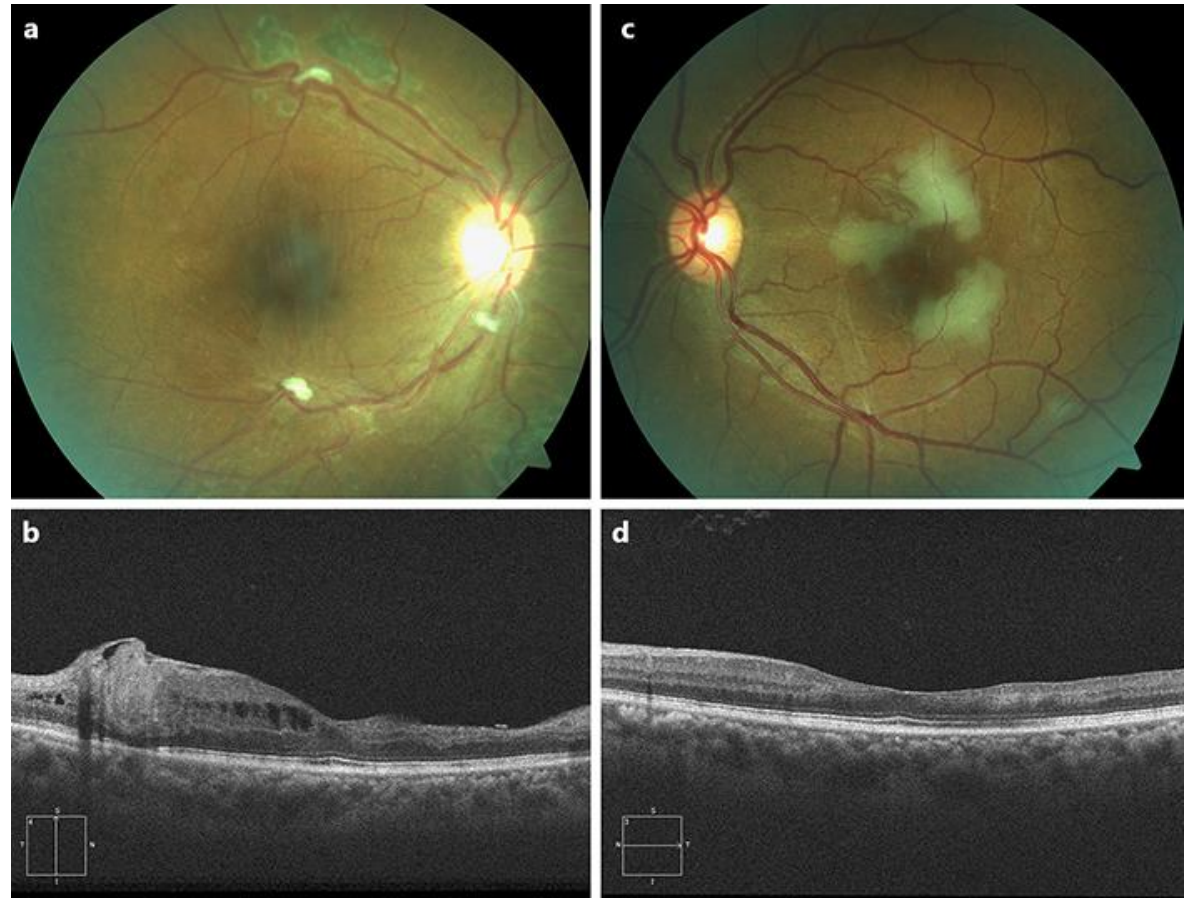

Fig. 4. a Color fundus photograph of the patient's right eye after vitrectomy to clear vitreous hemorrhage. Note the appearance of tractional membranes overlying the macula; partial segmentation had been performed, but delamination was avoided over the vascular arcade. Dark areas superiorly correspond to laser treatment. b Vertical Zeiss Cirrus ${ }^{\circledR}$ OCT cross-section of the right eye through the fovea, showing persistent tractional schisis of the macula. c Color photograph of the left eye, showing whitish areas of perifoveal edema consistent with multiple BRAO. $\mathbf{d}$ Horizontal OCT cross-section of the left eye through the fovea taken several weeks after the color image was taken, showing inner retinal atrophy suggestive of past retinal arterial infarct. 